\title{
Development and Characterization of Liposomal Doxorubicin Hydrochloride with Palm Oil
}

\author{
Bahareh Sabeti, ${ }^{1}$ Mohamed Ibrahim Noordin, ${ }^{1}$ Shaharuddin Mohd, ${ }^{2}$ \\ Rosnani Hashim, ${ }^{2}$ Afendi Dahlan, ${ }^{2}$ and Hamid Akbari Javar ${ }^{3}$ \\ ${ }^{1}$ Department of Pharmacy, Faculty of Medicine, University of Malaya, 51200 Kuala Lumpur, Malaysia \\ ${ }^{2}$ Faculty of Pharmacy, Cyberjaya University College of Medical Sciences, 63000 Cyberjaya, Selangor, Malaysia \\ ${ }^{3}$ Department of Pharmaceutics, Faculty of Pharmacy, Tehran University of Medical Sciences, Tehran 141176, Iran
}

Correspondence should be addressed to Hamid Akbari Javar; akbarijo@tums.ac.ir

Received 17 December 2013; Revised 11 February 2014; Accepted 17 February 2014; Published 27 March 2014

Academic Editor: Paolo Colombo

Copyright (C) 2014 Bahareh Sabeti et al. This is an open access article distributed under the Creative Commons Attribution License, which permits unrestricted use, distribution, and reproduction in any medium, provided the original work is properly cited.

\begin{abstract}
The usage of natural products in pharmaceuticals has steadily seen improvements over the last decade, and this study focuses on the utilization of palm oil in formulating liposomal doxorubicin (Dox). The liposomal form of Dox generally minimizes toxicity and enhances target delivery actions. Taking into account the antiproliferative and antioxidant properties of palm oil, the aim of this study is to design and characterize a new liposomal Dox by replacing phosphatidylcholine with $5 \%$ and $10 \%$ palm oil content. Liposomes were formed using the freeze_thaw method, and Dox was loaded through $\mathrm{pH}$ gradient technique and characterized through in vitro and ex vivo terms. Based on TEM images, large lamellar vesicles (LUV) were formed, with sizes of 438 and $453 \mathrm{~nm}$, having polydispersity index of $0.21 \pm 0.8$ and $0.22 \pm 1.3$ and zeta potentials of about -31 and $-32 \mathrm{mV}$, respectively. In both formulations, the entrapment efficiency was about $99 \%$, and whole Dox was released through 96 hours in $\mathrm{PBS}(\mathrm{pH}=7.4)$ at $37^{\circ} \mathrm{C}$. Comparing cytotoxicity and cellular uptake of LUV with Caelyx ${ }^{\mathrm{R}}$ on MCF7 and MDA-MBA 231 breast cancer cell lines indicated suitable uptake and lower IC50 of the prepared liposomes.
\end{abstract}

\section{Introduction}

Doxorubicin hydrochloride (Dox) is an antitumor antibiotic derived from anthracyclines. While the usage of anthracyclines is limited due to their dose-related cardiotoxicity and myelosuppression, applying liposomal Dox in ovary, lung, and breast cancer therapies has been approved by WHO due to its superior efficacy and minimum cardiotoxicity $[1,2]$. Furthermore, the liposomal forms allow Dox to remain in the circulation system for longer periods of time, which will allow for the delivery of a greater amount of the drug to cancerous cells or tumors $[1,3,4]$. Both the prolonged exposure of tumor cells to liposome and the capability to distinguish the differential between tumors via tissue cells are valuable reasons to develop liposomes. On the other hand, as nanoparticles are regarded as a valuable carrier, nanoliposome is also one of the well-known and established developments in drug delivery systems [5].
Since palm oil has antiproliferative and antioxidant properties due to presence of components such as carotenes, tocopherol, tocotrienols, terpenoids, and flavonoids, it is viable for use in pharmaceutical products, on top of its nutritional advantages. In addition, its antioxidants help resist rancidity and improve the stability of palm oil [6-8].

Considering the anticancer properties of palm oil and great advantages of liposome, the aim of this study was to prepare liposomal Dox by applying palm oil fractions.

\section{Materials}

Doxorubicin hydrochloride (Dox), palm oil (Po), cholesterol $(\mathrm{CH})$, L-alpha-phosphatidylcholine (PC), polyethylene glycol (PEG), methanol, and chloroform were purchased from Sigma-Aldrich (Germany). Sodium hydroxide and potassium 
dihydrogen phosphate were purchased from Merck (Germany).

\section{Method}

Liposomes were prepared using the freeze-thaw method and $\mathrm{pH}$ gradient technique, carried out in order to maximize the loading of Dox within liposome [9-11]. Two formulations were designed; both consisted of $45 \mathrm{mg} \mathrm{CH}$ and $5 \mathrm{mg}$ PEG with different percentages of $\mathrm{PC}$ and palm oil. The first formula $(\mathrm{Fa})$ contains $5 \%$ palm oil and $45 \%$ of $\mathrm{PC}$, while the second formula $(\mathrm{Fb})$ contains $10 \%$ palm oil and $40 \%$ PC in their respective formulations. Then, all of the lipid components and PEG were dissolved in a chloroform : methanol mixture of $(2: 1, \mathrm{v} / \mathrm{v})$ in a round-bottom flask. The solvent was removed under vacuum using a rotary evaporator (Rotavapour R-124, BÜCHI) at $40^{\circ} \mathrm{C}$ and $50 \mathrm{rpm}$. After a thin lipid film was formed in the interior of the flask, the system was purged with nitrogen to remove organic solvent entirely. The lipid film layer was hydrated with $10 \mathrm{~mL}$ Citrate buffered solution $(\mathrm{pH}=4)$ and then sonicated for 30 minutes in a bath type sonicator (Sonicor). The freeze-thaw cycle was carried out five times via freezing under $-80^{\circ} \mathrm{C}$ and then heated mixture in water bath at $65^{\circ} \mathrm{C}$ with the intention of decreasing the size, further entrapping the acidic buffer inside the liposome. Bicarbonate buffer $(\mathrm{pH}=0.5)$ was added dropwise to the mixture (for the reason of adjusting outer liposomes space into a physiological $\mathrm{pH}$ ) until its $\mathrm{pH}$ reaches 7. Afterwards, $10 \mathrm{~mL}$ of Dox medium in distilled water $(2000 \mu \mathrm{g} / \mathrm{mL})$ was added to the mixture and shaken at room temperature for 30 minutes at $60 \mathrm{rmp}$ [12-14].

3.1. Formation and Morphology. The formation of liposomes was observed with a transmission electron microscope (TEM). Samples were prepared by applying a drop of the mixture to a carbon-coated copper grid and left for a minute to allow some of the particles to adhere onto the carbon substrate. After removing the excess dispersion with a piece of filter paper, a drop of $1 \%$ phosphotungstic acid solution was applied for one minute and then left to be air-dried. The samples were viewed with a TEM (ABFETEM Leo 9112) [1417].

3.2. Particle Size Distribution, Polydispersity Index (PDI), and Zeta Potential (ZP) Measurement. To evaluate the size distribution, PDI, and value $\mathrm{ZP}$ of each sample, $50 \mathrm{mg}$ of liposome was weighted and dispersed in $20 \mathrm{~mL}$ distilled water and then those parameters were measured by the zetasizer (Zetasizer Nanoseries, Malbern Instrument) [18-20]. This test was repeated thrice.

3.3. Construction of Standard Curve. Dilutions of doxorubicin HCL were in the range of 400, 200, 100, 50, 25, and $12.5 \mathrm{ng} / \mathrm{mL}$, prepared and detected by HPLC with a fluorescence detector (Chromolith Performance RP-8e $100 \mathrm{~mm} \times 4.6 \mathrm{~mm}$ column protected by a Chromolith Guard
Cartridge RP-18e $5 \mathrm{~mm} \times 4.6 \mathrm{~mm}$, Merck, Darmstadt, Germany).

Mixture of Acetonitrile. Heptanesulfonic acid (0.2\%, pH 4) by a ratio of $25: 75$ was applied as mobile phase with the flow rate of $1 \mathrm{~mL} / \mathrm{min}$.

Dox has an excitation wavelength $\left(\lambda_{\text {ex }}\right)$ of $480 \mathrm{~nm}$ and an emission wavelength $\left(\lambda_{\mathrm{em}}\right)$ of $560 \mathrm{~nm}$. The calibration curve was constructed using the Microsoft Excel 2007 program $[19,21]$.

3.4. Evaluation of Entrapment Efficiency and In Vitro Release. The mixture was centrifuged (Universal 32) for 70 minutes at $14000 \mathrm{rpm}$, the supernatant containing free Dox was obtained, and the absorbance was measured using HPLC [15]. The entrapment efficiency of liposomes was determined by the following formula:

$$
\mathrm{EE}(\%)=\left\{\frac{\left(C_{i}-C_{f}\right)}{C_{i}}\right\} \times 100,
$$

where EE is the concentration of entrapped drug $(\mathrm{ng} / \mathrm{mL})$, $C_{i}$ is the initial concentration of drug used in formulating the liposomes $(\mathrm{ng} / \mathrm{mL}), C_{f}$ is the concentration of drug in the supernatant $(\mathrm{ng} / \mathrm{mL})$, and $\mathrm{EE}(\%)$ is the percentage of the drug's entrapment.

To estimate the in vitro drug release of liposomal Dox, a dialysis bag was used [22]. After separating free drug, $100 \mathrm{mg}$ of liposome was weighted and then placed directly into the dialysis bag (Mw12000). The dialysis bag was sealed at both ends and located in a $1000 \mathrm{~mL}$ fresh PBS buffer medium $(\mathrm{pH}$ 7.4 ) at $37^{\circ} \mathrm{C}$, at $90 \mathrm{rpm}$ under perfect sink conditions $[15,23$, 24]. At predetermined time intervals, $1 \mathrm{~mL}$ of the medium was sampled for further analysis by HPLC. The concentrations of doxorubicin throughout the releasing time were calibrated using the calibration equation. The results recorded are the mean value of the three runs carried out for each liposome concentration. The percentage of released Dox at certain time was plotted using Microsoft Excel 2007 and was defined by the following formula:

$$
\text { Drug release }(\%)=\left(\frac{C_{t} \times 10^{-3}}{C_{i}}\right) \times 100,
$$

where $C_{t}$ is the concentration of drug released $(\mathrm{ng} / \mathrm{mL})$ at time $t$ and $C_{i}$ is the initial drug concentration $(\mathrm{ng} / \mathrm{mL})$.

3.5. Cellular Uptake. To observe the cellular uptake, two breast cancer cell lines, received from Pasture Institute, were utilized separately. MCF-7 cells were cultured in RPMI 1640, and $10 \%$ FBS were then seeded in 24-well plates with a density of $1 \times 10^{5}$ cells/well and incubated in $37^{\circ} \mathrm{C}$ with $5 \%$ $\mathrm{CO}_{2}$ for $24 \mathrm{~h} .50 \mu \mathrm{L}$ Dox liposome $(2000 \mu \mathrm{g} / \mathrm{mL})$ was added into each well and incubated for $24 \mathrm{~h}$, and then the cells were washed thrice with BPS, respectively. Afterward, image analyses of cells were performed with confocal microscopy (IX71, Olympus, Japan), and the same procedure was carried out for MDA-MBA, 231 cells as well $[25,26]$. 


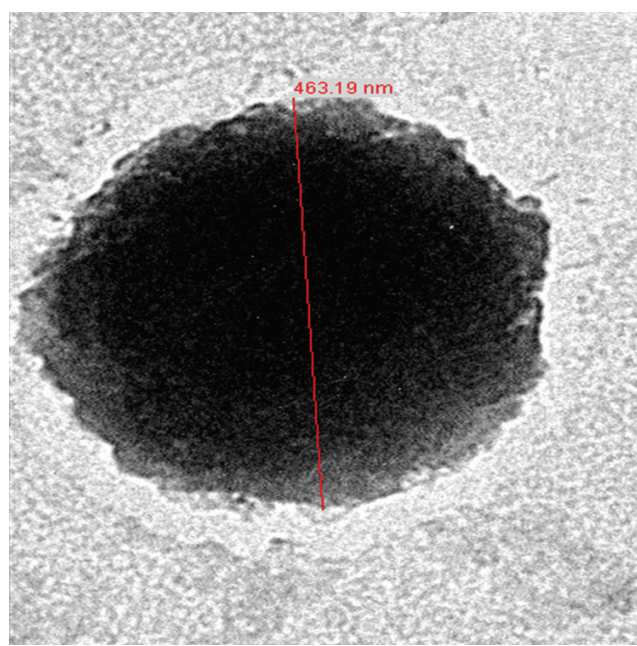

(a)

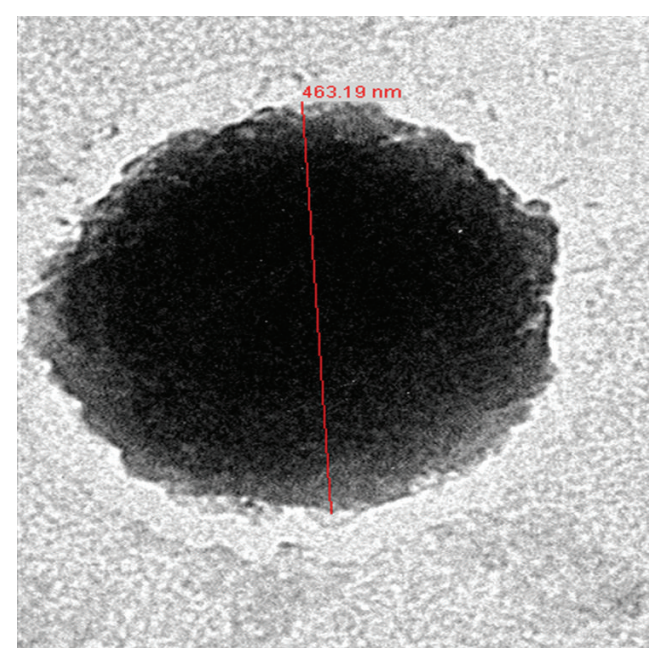

(b)

Figure 1: TEM images of Dox liposome with magnification 8000x, (a) (Fa), (b) (Fb).

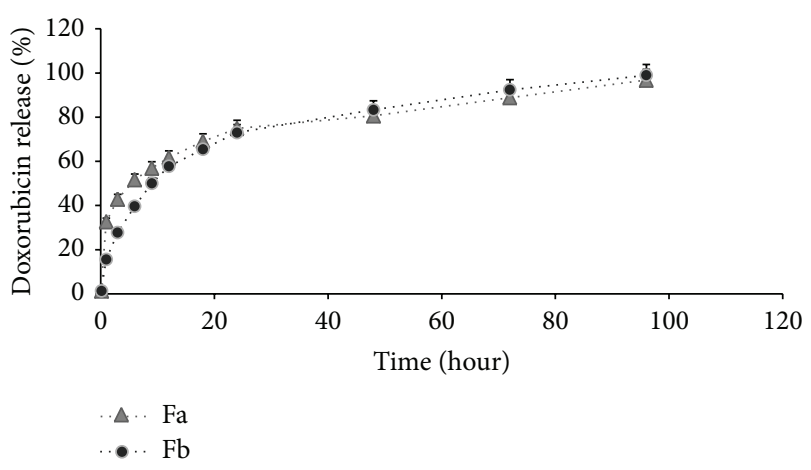

FIGURE 2: Cumulative release of doxorubicin in PBS ( $\mathrm{pH}$ 7.4). Key: $\mathrm{Fa}$ (grey triangle), $\mathrm{Fb}(\bullet)$.

3.6. Cytotoxicity Assay. MTT assay was performed to observe the cytotoxic activities of designed liposome, IC50 of formulation assessed in cell culture media and compared with Caely $^{\mathrm{R}}$ (pegylated liposomal Dox). The human breast cell lines MCF 7 and MDA-MBA 231 were seeded in 96-well plates with a density of $7 \times 10^{3}$ cells/well, using RPMI 1640 and $10 \%$ FBS added and then incubated in $37^{\circ} \mathrm{C}$ with $5 \% \mathrm{CO}_{2}$ for $24 \mathrm{~h}$. The cells were then treated with various concentrations of Caelyx $^{\mathrm{R}}(2000 \mu \mathrm{g} / \mathrm{mL}), \mathrm{Fa}$, and $\mathrm{Fb}$ (liposome containing 5\% and $10 \%$ of palm oil loaded with $2000 \mu \mathrm{g} / \mathrm{mL}$ doxorubicin, which is in the same concentration of Caely $x^{\mathrm{R}}$ ), respectively, and then incubated for $48 \mathrm{~h}$. Afterwards, the media were removed, and $10 \mu \mathrm{L}$ MTT was added to each well, incubated for a further four hours. Finally, the MTT was removed, and $100 \mu \mathrm{L}$ DMSO was added to each well, and the absorbance was measured with an ELISA reader at $\lambda=595 \mathrm{~nm}$ [27-29].

3.7. Statistical Analysis. All of the results were remarked with the mean $\pm S D$, and the one-way analysis of variance (ANOVA) was employed for statistical analysis of the data, followed by Scheffe post hoc test using (SPSS 15 for Windows 7). Differences were considered significant at $P<0.05$.

\section{Results and Discussion}

4.1. Liposomes Formation and Morphology. TEM images in Figure 1 demonstrate the formation of vesicles. Considering the TEM images, one layer liposome with large inside capacity confirms the fine formation and well shape of the LUV in both formulations.

4.2. Particle Size Distribution and Zeta Potential Measurement. Particle size determinations are mostly performed to confirm that the desired liposome size range has been obtained during preparation because suitable size of particles is important for their interaction with the biological situation; for instance, through intravenous administration of loaded particles, their ability to pass or leave the vascular capillaries effectively is dependent on the sizing $[18,30]$. Referring to Table 1, Fa has a size of $438.74 \pm 1.9 \mathrm{~nm}$, while $\mathrm{Fb}$ has a size of $453.71 \pm 1.1 \mathrm{~nm}$; the nanosize of LUVs would result in advance drug delivery.

The polydispersity index value is a measure of the heterogeneity of particle sizes in a compound. Liposomes with PDI value between 0.1 and 0.25 display more uniformity and physical stability. Further PDI value more than 0.5 indicates the poor uniformity of mixture $[20,31]$. Looking at Table 1, the PDI values of liposomes are $0.22 \pm 1.3$ and $0.21 \pm 0.8$ which confirm the uniformity and homogeneity of LUVs in the mixture as well [32].

The value of zeta potential (ZP) proves the stability of the particulate systems. It is a measurement of the repulsive forces between the particles. Particles having a $\mathrm{ZP}$ of less than $-30 \mathrm{mV}$ or more than $+30 \mathrm{mV}$ are usually regarded as stable. Considering the $\mathrm{ZP}$ values were higher than $-30 \mathrm{mV}$ (Table 2), which confirms the acceptable stability of LUVs 


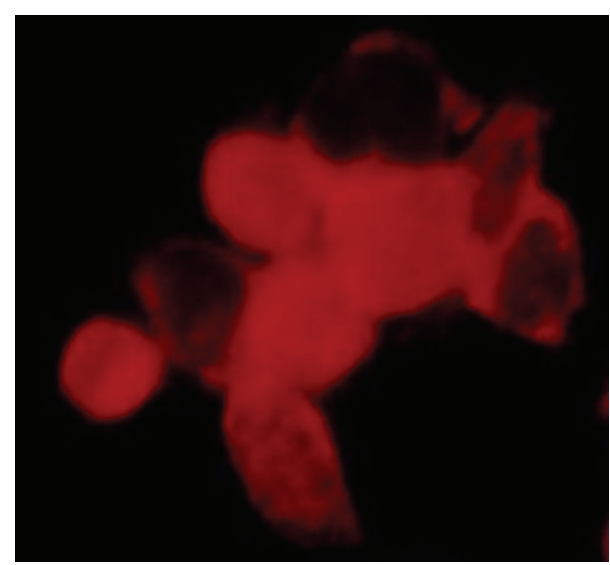

(a)

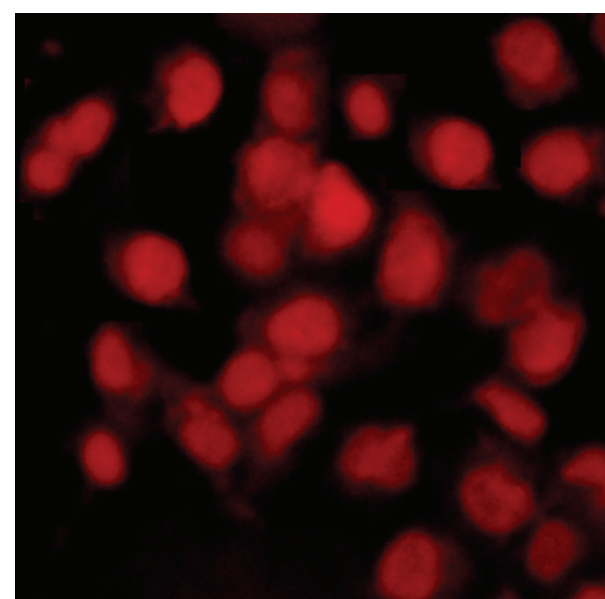

(c)

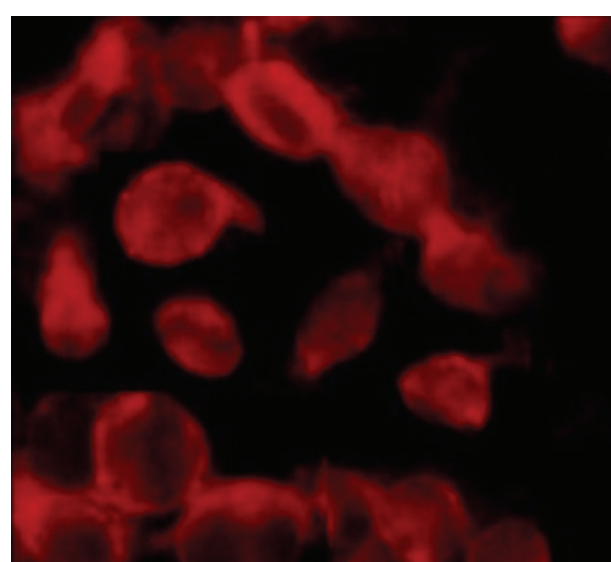

(b)

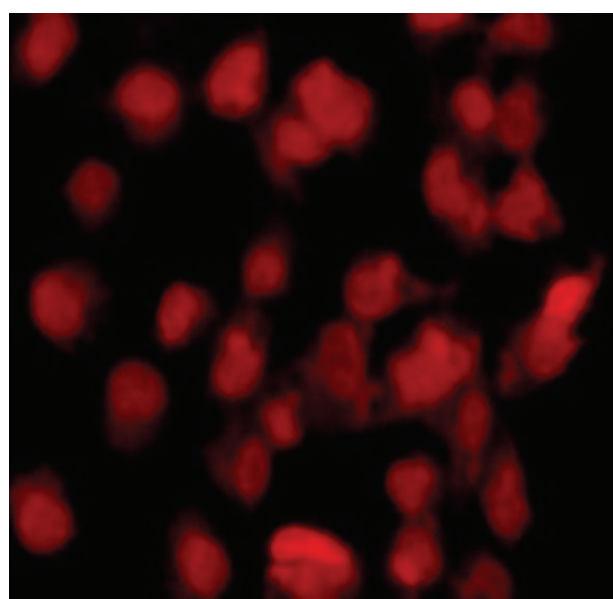

(d)

FIGURE 3: Cellular uptake of Dox liposome: (a) Fa liposome in MCF 7 cells, (b) Fb liposome in MCF 7 cells, (c) Fa liposome in MDA-MBA 231 cells, and (d) Fb liposome in MDA-MBA 231 cells.

as well as their uniformity and size homogeneity suspension [18-20].

4.3. Construction of Calibration Curve. The following equation from the HPLC results was obtained: $Y=21998 X+8938$, where $Y$ is the area under the curve and $X$ is the concentration of doxorubicin; the regression line of $R^{2}=0.999$ was obtained as well.

4.4. Entrapment Efficiency and In Vitro Drug Release. As seen from Table 1, in both formulations, liposomes contained maximum entrapment efficiency, nearly $100 \%$, using the $\mathrm{pH}$ gradient technique $[12,13,15]$.

Figure 2 shows the in vitro release of Dox during 96 hours where both formulations demonstrate a constant and continuous release profile. Since $\mathrm{Fa}$ and $\mathrm{Fb}$ liposomes include same ingredient with only difference in amount of PC and palm oil, they also have comparable releasing pattern with small variation. Within the first 6 hours, Fa demonstrated a faster release rate compared to Fb. During 6-24 hours, Fa and
Fb liposomes showed almost similar release whereas, after 36 hours, Fa release goes slower than $\mathrm{Fb}$; however no significant difference is observed.

4.5. Cellular Uptake and Cytotoxicity. Figure 3 demonstrates the cellular fluorescence images and cellular uptake of the Dox after the cells were incubated with liposome for $24 \mathrm{~h}$. As Dox emits red fluorescence, the presence of Dox liposome can be clearly observed in MCF-7 and MDA-MBA 231 cells. After incubation of cell lines with Dox liposomes, they would cross the cell's membrane and the viable cells appear to have a red basis, while the apoptosis cells exhibited brighter reds, respectively [26-29].

As seen from Table 2, the IC50 of designed liposomal Dox and Caelyx ${ }^{\mathrm{R}}$ on breast cancer cell lines were compared. In MCF-7 cells the IC50 for liposomal Dox with palm oil was $376.45 \pm 9.20$ and $387.22 \pm 6.93 \mu \mathrm{g} / \mathrm{mL}$ which is more effective than Caelyx ${ }^{\mathrm{R}}$ with $483.84 \pm 7.78 \mu \mathrm{g} / \mathrm{mL}$. Similarly, in MDA_MBA23 cells, the IC50 for designed liposome is $726.40 \pm 7.58$ and $755.73 \pm 6.81 \mu \mathrm{g} / \mathrm{mL}$ while it is 
TABLE 1: Particle size, zeta potential, and entrapment efficiency of the liposomes.

\begin{tabular}{lcccc}
\hline Formulation & $\begin{array}{c}\text { Mean } \\
\text { particle size } \\
(\mathrm{nm}, \pm \mathrm{SD})\end{array}$ & $\begin{array}{c}\text { Mean } \\
\text { zeta potential } \\
(\mathrm{mV}, \pm \mathrm{SD})\end{array}$ & $\begin{array}{c}\text { Mean } \\
\text { polydispersity index } \\
(\mathrm{PDI})\end{array}$ & $\begin{array}{c}\text { Mean } \\
\text { entrapment efficiency } \\
(\%, \pm S D)\end{array}$ \\
\hline $\mathrm{Fa}$ & $438.74 \pm 1.9$ & $-31.1 \pm 2.6$ & $0.22 \pm 1.3$ & $99.98 \pm 3.18$ \\
$\mathrm{Fb}$ & $453.71 \pm 1.1$ & $-32.2 \pm 4.1$ & $0.21 \pm 0.8$ & $99.99 \pm 5.22$ \\
\hline
\end{tabular}

TABLe 2: IC50 of Fa, Fb, and Caelyx ${ }^{\mathrm{R}}$ after 48 hours of treatment.

\begin{tabular}{lcc}
\hline Formulation & $\begin{array}{c}\text { IC50 MCF7 } \\
(\mu \mathrm{g} / \mathrm{mL}, n=3)\end{array}$ & $\begin{array}{c}\text { IC50 MDA-MBA 231 } \\
(\mu \mathrm{g} / \mathrm{mL}, n=3)\end{array}$ \\
\hline $\mathrm{Fa}$ & $376.45 \pm 9.20$ & $726.40 \pm 7.58$ \\
$\mathrm{Fb}$ & $387.22 \pm 6.93$ & $755.73 \pm 6.81$ \\
Caelyx $^{\mathrm{R}}$ & $483.84 \pm 7.78$ & $972.91 \pm 9.87$
\end{tabular}

$972.91 \pm 9.87 \mu \mathrm{g} / \mathrm{mL}$ for Caelyx ${ }^{\mathrm{R}}$. In addition, potent IC50 in MCF-7 cell line indicates that MCF-7 cells are more sensitive to liposomal Dox than the MDA_MBA23 cells [25-29].

\section{Conclusion}

In order to take advantage of the therapeutic effects of palm oil, liposomal Dox formulations were prepared by replacing PC with different ratios of palm oil. Liposomal formulations containing $5 \%$ and $10 \%$ of palm oil were made through the freeze-thaw method, and then the TEM images revealed satisfactory morphology and formation of LUVs, respectively. Liposomal size distribution, zeta potential, and stability remain in the acceptable range. The HPLC results confirm the optimal drug loading through $\mathrm{pH}$ gradient technique and sophisticated in vitro release profile as well.

The finest cellular uptake was observed on MCF-7 and MDA-MBA 231 cell lines through $24 \mathrm{~h}$; furthermore, cytotoxicity assay confirms the more effectiveness of the liposomal Dox containing palm oil in comparison to Caelyx ${ }^{R}$.

\section{Conflict of Interests}

The authors declare that there is no conflict of interests regarding the publication of this paper.

\section{Acknowledgments}

This research work was funded by ERGS Grant ERGS/1/ 2011/SKK/CUCMS/03/3 and also supported by Cyberjaya University Collage of Medical University (CUCMS), University of Malaya (UM), and Tehran University of Medical Sciences (TUMS).

\section{References}

[1] O. Tacar, P. Sriamornsak, and C. R. Dass, "Doxorubicin: an update on anticancer molecular action, toxicity and novel drug delivery systems," Journal of Pharmacy and Pharmacology, vol. 65, no. 2, pp. 157-170, 2013.
[2] A. A. Gabizon, O. Lyass, G. J. Berry, and M. Wildgust, "Cardiac safety of pegylated liposomal doxorubicin (Doxil/Caelyx) demonstrated by endomyocardial biopsy in patients with advanced malignancies," Cancer Investigation, vol. 22, no. 5, pp. 663-669, 2004.

[3] A. A. Gabizon, "Selective tumor localization and improved therapeutic index of anthracyclines encapsulated in long-circulating liposomes," Cancer Research, vol. 52, no. 4, pp. 891-896, 1992.

[4] A. Gabizon, D. Goren, A. T. Horowitz, D. Tzemach, A. Lossos, and T. Siegal, "Long-circulating liposomes for drug delivery in cancer therapy: a review of biodistribution studies in tumorbearing animals," Advanced Drug Delivery Reviews, vol. 24, no. 2-3, pp. 337-344, 1997.

[5] V. P. Torchilin, "Recent advances with liposomes as pharmaceutical carriers," Nature Reviews Drug Discovery, vol. 4, no. 2, pp. 145-160, 2005.

[6] D. O. Edem, "Palm oil: biochemical, physiological, nutritional, hematological, and toxicological aspects: a review," Plant Foods for Human Nutrition, vol. 57, no. 3-4, pp. 319-341, 2002.

[7] C. E. Elson and A. A. Qureshi, "Coupling the cholesteroland tumor-suppressive actions of palm oil to the impact of its minor constituents on 3-hydroxy-3-methylglutaryl coenzyme a reductase activity," Prostaglandins Leukotrienes and Essential Fatty Acids, vol. 52, no. 2-3, pp. 205-208, 1995.

[8] J. P. Kamat and T. P. A. Devasagayam, "Tocotrienols from palm oil as potent inhibitors of lipid peroxidation and protein oxidation in rat brain mitochondria," Neuroscience Letters, vol. 195, no. 3, pp. 179-182, 1995.

[9] M. R. Mozafari, "Liposomes: an overview of manufacturing techniques," Cellular and Molecular Biology Letters, vol. 10, no. 4, pp. 711-719, 2005.

[10] M. Riaz, "Liposomes preparation methods," Pakistan Journal of Pharmaceutical Sciences, vol. 19, no. 1, pp. 65-77, 1996.

[11] L. D. Mayer, L. C. L. Tai, M. B. Bally, G. N. Mitilenes, R. S. Ginsberg, and P. R. Cullis, "Characterization of liposomal systems containing doxorubicin entrapped in response to $\mathrm{pH}$ gradients," Biochimica et Biophysica Acta, vol. 1025, no. 2, pp. 143-151, 1990.

[12] G. Gregoriadis, "Entrapment of drugs and other materials into liposomes," in Liposome Technology, vol. 2, Informa HealthCare, 3rd edition, 2007.

[13] G. Niu, B. Cogburn, and J. Hughes, "Preparation and characterization of doxorubicin liposomes," in Cancer Nanotechnology, pp. 211-219, Springer, 2010.

[14] M. Traikia, D. E. Warschawski, M. Recouvreur, J. Cartaud, and P. F. Devaux, "Formation of unilamellar vesicles by repetitive freeze-thaw cycles: characterization by electron microscopy and 31P-nuclear magnetic resonance," European Biophysics Journal, vol. 29, no. 3, pp. 184-195, 2000.

[15] X. Mu and Z. Zhong, "Preparation and properties of poly(vinyl alcohol)-stabilized liposomes," International Journal of Pharmaceutics, vol. 318, no. 1-2, pp. 55-61, 2006. 
[16] M. Almgren, K. Edwards, and G. Karlsson, "Cryo transmission electron microscopy of liposomes and related structures," Colloids and Surfaces A, vol. 174, no. 1-2, pp. 3-21, 2000.

[17] P. N. Gupta, V. Mishra, A. Rawat et al., "Non-invasive vaccine delivery in transfersomes, niosomes and liposomes: a comparative study," International Journal of Pharmaceutics, vol. 293, no. 1-2, pp. 73-82, 2005.

[18] N. Heldt, M. Gauger, J. Zhao, G. Slack, J. Pietryka, and Y. $\mathrm{Li}$, "Characterization of a polymer-stabilized liposome system," Reactive and Functional Polymers, vol. 48, no. 1, pp. 181-191, 2001.

[19] S. Fogli, R. Danesi, F. Innocenti et al., "An improved HPLC method for therapeutic drug monitoring of daunorubicin, idarubicin, doxorubicin, epirubicin, and their 13-dihydro metabolites in human plasma," Therapeutic Drug Monitoring, vol. 21, no. 3, pp. 367-375, 1999.

[20] J. Pereira-Lachataignerais, R. Pons, P. Panizza, L. Courbin, J. Rouch, and O. López, "Study and formation of vesicle systems with low polydispersity index by ultrasound method," Chemistry and Physics of Lipids, vol. 140, no. 1-2, pp. 88-97, 2006.

[21] C. Mazuel, J. Grove, G. Gerin, and K. P. Keenan, "HPLC-MS/MS determination of a peptide conjugate prodrug of doxorubicin, and its active metabolites, leucine-doxorubicin and doxorubicin, in dog and rat plasma," Journal of Pharmaceutical and Biomedical Analysis, vol. 33, no. 5, pp. 1093-1102, 2003.

[22] P. Panwar, B. Pandey, P. C. Lakhera, and K. P. Singh, "Preparation, characterization, and in vitro release study of albendazoleencapsulated nanosize liposomes," International Journal of Nanomedicine, vol. 5, no. 1, pp. 101-108, 2010.

[23] P. Saarinen-Savolainen, T. Järvinen, H. Taipale, and A. Urtti, "Method for evaluating drug release from liposomes in sink conditions," International Journal of Pharmaceutics, vol. 159, no. 1, pp. 27-33, 1997.

[24] M. Sznitowska and M. Stokrocka, "Determination of diclofenac released from suppositories using UV spectrophotometry, spectra derivative spectrophotometry and HPLC, Acta Poloniae Pharmaceutica, vol. 64, no. 5, pp. 401-405, 2007.

[25] A. Iwasa, H. Akita, I. Khalil, K. Kogure, S. Futaki, and H. Harashima, "Cellular uptake and subsequent intracellular trafficking of R8-liposomes introduced at low temperature," Biochimica et Biophysica Acta, vol. 1758, no. 6, pp. 713-720, 2006.

[26] A. Miglietta, R. Cavalli, C. Bocca, L. Gabriel, and M. Rosa Gasco, "Cellular uptake and cytotoxicity of solid lipid nanospheres (SLN) incorporating doxorubicin or paclitaxel," International Journal of Pharmaceutics, vol. 210, no. 1-2, pp. 6167, 2000.

[27] F.-Q. Hu, X.-L. Wu, Y.-Z. Du, J. You, and H. Yuan, "Cellular uptake and cytotoxicity of shell crosslinked stearic acid-grafted chitosan oligosaccharide micelles encapsulating doxorubicin," European Journal of Pharmaceutics and Biopharmaceutics, vol. 69, no. 1, pp. 117-125, 2008.

[28] S. Park and H. S. Yoo, "In vivo and in vitro anti-cancer activities and enhanced cellular uptakes of EGF fragment decorated doxorubicin nano-aggregates," International Journal of Pharmaceutics, vol. 383, no. 1-2, pp. 178-185, 2010.

[29] H. Yuan, J. Miao, Y.-Z. Du, J. You, F.-Q. Hu, and S. Zeng, "Cellular uptake of solid lipid nanoparticles and cytotoxicity of encapsulated paclitaxel in A549 cancer cells," International Journal of Pharmaceutics, vol. 348, no. 1-2, pp. 137-145, 2008.

[30] C. Nastruzzi, Lipospheres in Drug Targets and Delivery: Approaches, Methods, and Applications, CRC Press, 2004.

[31] M. Cheng, X. Gao, Y. Wang et al., "Synthesis of glycyrrhetinic acid-modified chitosan 5-fluorouracil nanoparticles and its inhibition of liver cancer characteristics in vitro and in vivo," Marine Drugs, vol. 11, no. 9, pp. 3517-3536, 2013.

[32] R. G. Gilbert, M. Hess, A. D. Jenkins, R. G. Jones, P. Kratochvíl, and R. F. T. Stepto, "Dispersity in polymer science," Pure and Applied Chemistry, vol. 81, no. 2, pp. 351-353, 2009. 

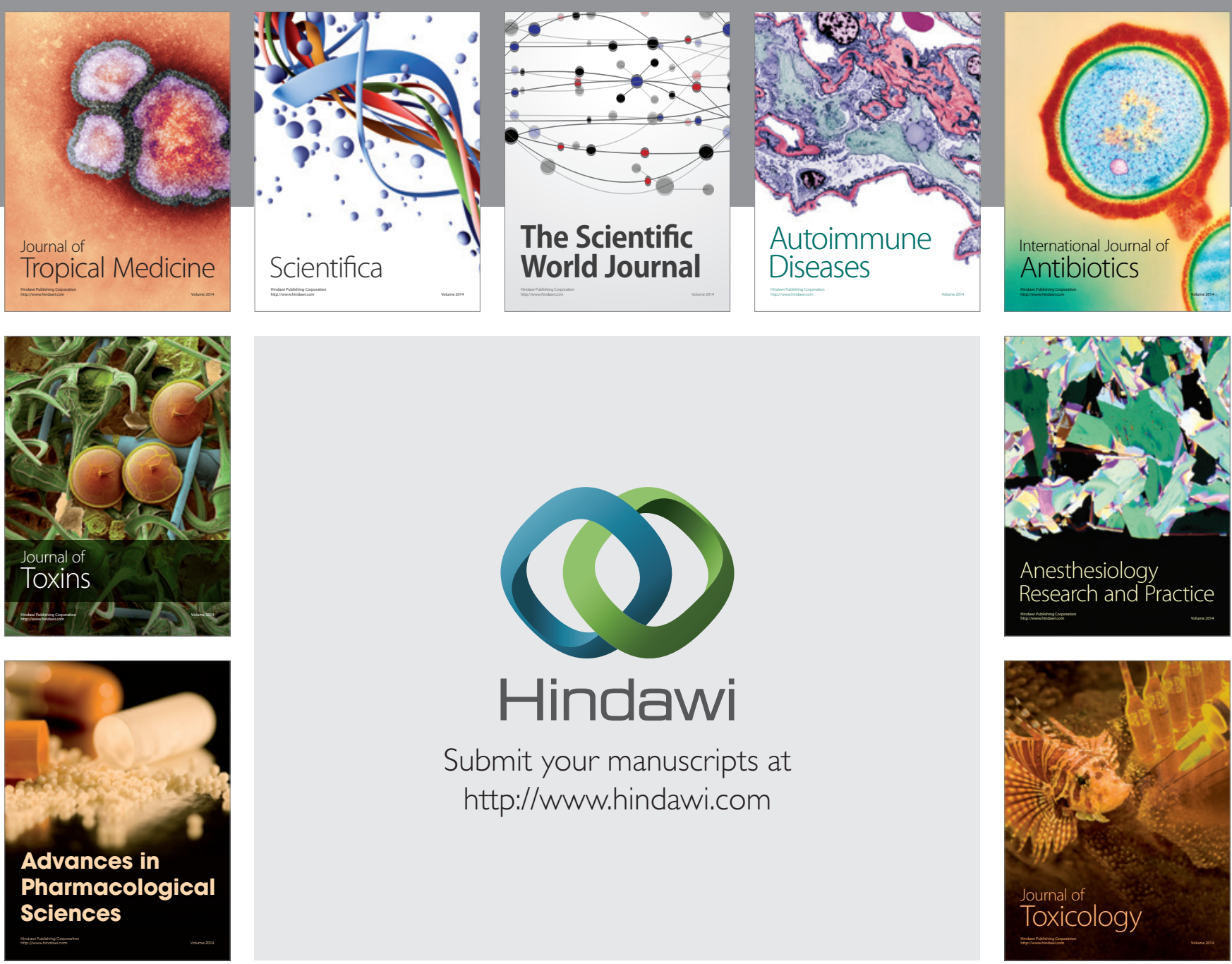

\section{Hindawi}

Submit your manuscripts at

http://www.hindawi.com
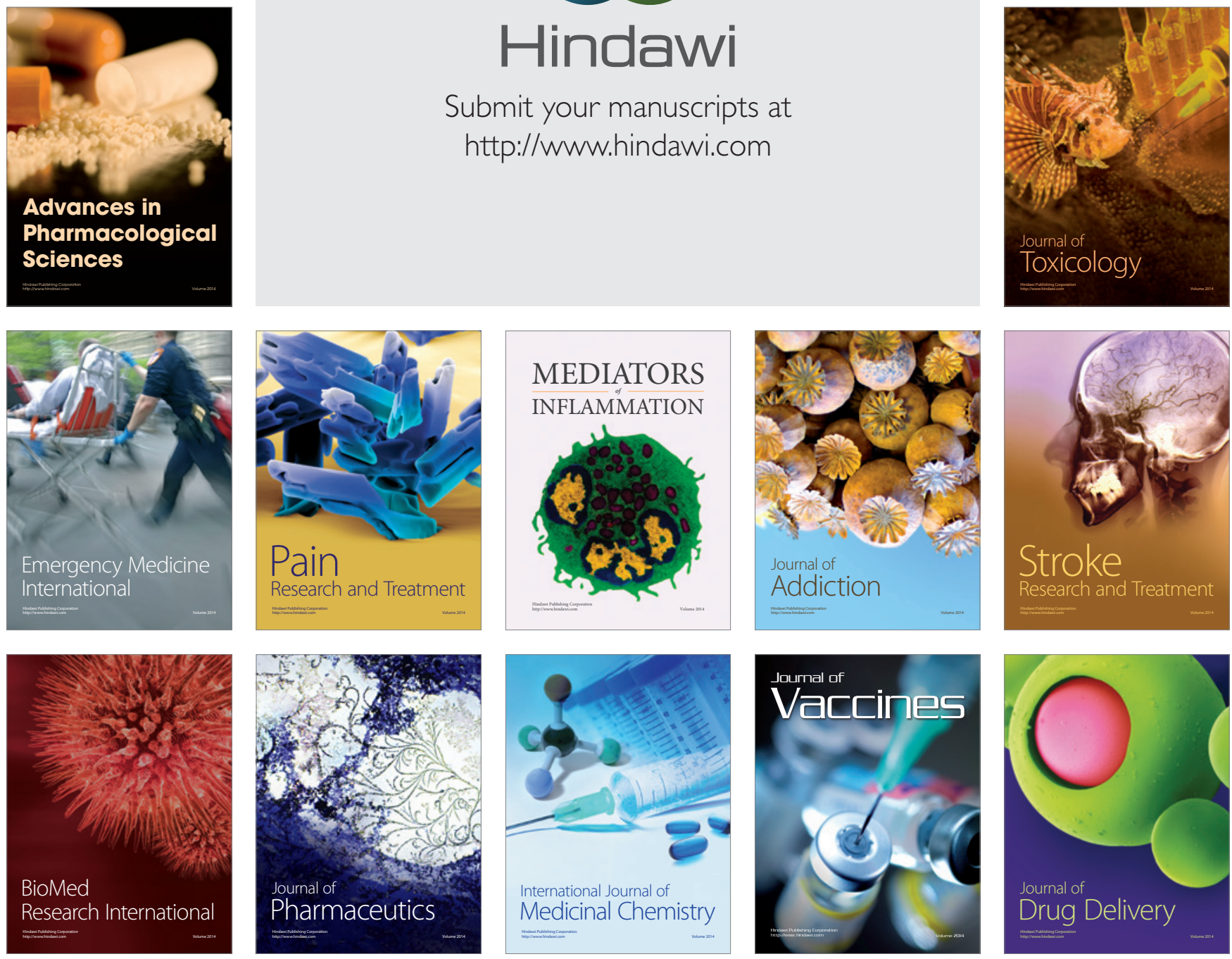